\title{
Patent Pools and Cross-Licensing in the Shadow of Patent Litigation*
}

\author{
by \\ Jay Pil Choi ${ }^{1}$ \\ Michigan State University, U.S.A. and Yonsei University, Korea
}

\begin{abstract}
This paper develops a framework to analyze the incentives to form a patent pool or engage in cross-licensing arrangements in the presence of uncertainty about the validity and coverage of patents that makes disputes inevitable. It analyzes the private incentives to litigate and compares them with the social incentives. It shows that pooling arrangements can have the effect of sheltering invalid patents from challenges. This result has an antitrust implication that patent pools should not be permitted until after patentees have challenged the validity of each other's patents if litigation costs are not too large.
\end{abstract}

\section{Shortened Title: Patent Pools and Litigation}

\footnotetext{
* Manuscript received December 2007; revised September 2008.

${ }^{1}$ I thank the Co-Editor and two anonymous referees for very constructive comments and suggestions that helped improve the paper significantly. I am also grateful to Robert Hunt, Corinne Langinier, Josh Lerner, GianCarlo Moschini, Ines Macho-Stadler, Jennifer Reinganum, Santanu Roy, and participants in various conferences and seminars for helpful comments. Please address correspondence to: Jay Pil Choi, Department of Economics, 110 Marshall-Adams Hall, Michigan State University, East Lansing, MI 48824, U.S.A. Phone: (517) 353-7281. Fax: (517) 432-1068. E-mail: choijay@msu.edu.
} 


\section{Introduction}

This paper develops a model of patent pools/cross-licensing in which the incentives to litigate are explicitly taken into account in the formation of patent pools. The basic premise of the paper is that patent rights are inherently probabilistic and subject to disputes. Even though the literature on patent protection has assumed ironclad patents and no uncertainty regarding patent claims until recently, the reality is that the extent to which protection is provided by the patent is not precise, and even the validity of the patent itself can be challenged in the courts. ${ }^{2}$ Moreover, as emphasized by Scotchmer (1991), the innovation process is typically cumulative with innovations building on each other and requiring multiple patents for the practice of technology. ${ }^{3}$ As a result, we observe a myriad of patent infringement suits through which questions of utility, novelty, and nonobviousness are independently ruled on by a court. ${ }^{4}$

The majority of these disputes, however, are settled out of court rather than litigated to a final resolution. ${ }^{5}$ In fact, many patent pools and cross-licensing arrangements arise as an attempt to settle disputes on conflicting claims in the litigation

\footnotetext{
${ }^{2}$ For instance, the "doctrine of equivalents" entitles the patented invention to cover a certain range of equivalents. However, the exact boundary of the equivalents is impossible to draw. The matter of infringement can be reasonably assumed to be decided case by case. See Lemley and Shapiro (2005) for an excellent survey of the burgeoning literature on probabilistic patents.

3 See also Green and Scotchmer (1995) and O’Donoghue, Scotchmer and Thisse (1998).

${ }^{4}$ According to Allison and Lemley (1998), nearly half (46\%) of fully litigated patents are declared invalid, which illustrates the importance of court decisions on patent validity in infringement suits. See Lanjouw and Schankerman (2001) for an empirical analysis of patent litigation.

${ }^{5}$ Lanjouw and Schankerman (2002) report that 95\% of patent lawsuits are settled prior to a court judgment.
} 
process or in expectation of impending litigation. ${ }^{6}$ To reflect this reality, this paper develops a simple framework to analyze the incentives to form a patent pool or engage in cross-licensing arrangements in the presence of uncertainty about the validity of the patents. It analyzes the private incentives to litigate and compares them with the social incentives. It shows that pooling arrangements can have the effect of sheltering invalid patents from challenges. This result has an antitrust implication that patent pools should not be permitted until after patentees have challenged the validity of each other's patents if litigation costs are not too large.

To analyze patent pools with probabilistic patents, I adopt the framework developed by Lerner and Tirole (2004) that can encompass the whole range of relationships between patents including perfectly substitutable and complementary patents. It is shown that the scope for public policy can be very different depending on the nature of relationship between patents. With ironclad patents, patent pools are procompetitive when the relationship is relatively complementary, as they correct an externality that leads to excessive royalty rates. Social and private incentives to form a patent pool are completely aligned. The case with substitute patents is very different. Patent pools tend to be anticompetitive and social and private incentives to form them may be quite divergent.

\footnotetext{
${ }^{6}$ According to Shapiro (2003), "[v]irtually every patent license can be viewed as a settlement of a patent dispute: the royalty rate presumably reflects the two parties' strengths or weaknesses in patent litigation in conjunction with the licensee's ability to invent around the patent. The same is true of cross-licenses, where net payments reflect the strength of each party's patent portfolio along with its commercial exposure to the other's patents."
} 
In the presence of litigation with uncertain patents, I make a distinction between ex ante and ex post patent pools. Ex ante patent pools are formed when patents considered for patent pools have not yet been contested in the court and thus their validities are uncertain. Ex post patent pools are formed after the validities of patents in consideration have been contested in court and thus there is no uncertainty about their validities. The ex post optimal patent policy replicates the optimal rule with ironclad patents. In contrast, the ex ante optimal patent policy depends on litigation incentives of private parties when the ex ante patent pool is not allowed. It is shown that ex ante patent pools should not be allowed if private parties have incentives to litigate and the patent policy is ex post optimal. However, if no firm has incentive to litigate, the optimal policy is to allow patents if they are relatively complementary, as with ironclad patents. Since private firms lack incentives to litigate each other when patents are weak, we derive a paradoxical result that paten pools should be allowed when patents have suspect value in the case of complementary patents.

I also analyze patent disputes that concern the relative priority of patents to check the robustness of the results. Once again, I find that there is a divergence in private and social incentives in the formation of patent pools. In addition, I find a discrepancy between private and social incentives to litigate when patent pools are not allowed. Litigation occurs when patents are strong, while on welfare grounds litigation should take place when patents are weak.

This paper is closely related to Shapiro (2003) who also recognizes that IPR associated with patents are inherently uncertain or imperfect, at least until they have successfully survived a challenge in court. He proposes a general rule for evaluating 
proposed patent settlements, which is to require that "the proposed settlement generate at least as much surplus for consumers as they would have enjoyed had the settlement not been reached and the dispute instead been resolved through litigation." ${ }^{\prime 7} \mathrm{He}$ convincingly argues that such a rule would fully respect intellectual property rights while protecting the interest of consumers. However, his paper does not analyze the incentives to litigate in the first place by just assuming that there would be patent disputes. My paper points out that the most serious case arises when both firms have weak patents and do not have any incentive to challenge each other. In such a case, public policy should be geared towards providing incentives for other concerned parties to challenge weak patents. A recent paper by Farrell and Shapiro (2008) also analyzes the licensing of patents that may be invalid to licensees who compete in a downstream product market. They show that weak patents can command surprisingly large per-unit royalties when licensed to a group of downstream oligopolists, and call for patent reform. ${ }^{8}$ However, they do not explicitly analyze the incentives to litigate.

Lerner and Tirole (2004) build a model of a patent pool in which they provide a necessary and sufficient condition for a patent pool to enhance welfare. They extend their model in several directions to analyze various issues related to patent pools. These issues include the evaluation of the "external test" that does not allow inclusion of substitute patents in a pool, the rationale for the provision of automatic assignment of future related patents to the pool, and the pool members' incentives to invent around each

\footnotetext{
${ }^{7}$ Shapiro (2003, p. 393). See also Priest (1977) for an early analysis of patent licensing as a disguise for cartel arrangements.

${ }^{8}$ In particular, Farrell and Shapiro (2008) show that in a symmetric Cournot oligopoly with constant marginal costs, the royalty rate for a weak patent is proportional to the number of downstream firms.
} 
other 's patents. ${ }^{9}$ However, litigation incentives are tangential to their analysis. My paper and Lerner and Tirole (2004) focus on different aspects of patent pools and thus should be viewed as complementary.

Finally, Gilbert (2004) reviews the history of patent pools and evaluates the performance of courts through the lens of economic analysis. He makes an argument that the most important factor in the legal evaluation of patent pools and cross-licensing arrangements should be the competitive relationships among the patents involved. In his review of the legal cases, however, he finds that the most decisive factor in courts' determination of whether patent pools have violated antitrust laws has been restrictive licensing terms. Gilbert (2004) also points out that the social return from challenges to weak patents is much higher than the private return and makes a recommendation that antitrust agencies become more proactive in this area. This paper provides theoretical support for both of his arguments.

The remainder of the paper is organized in the following way. In section 2, I set up the basic model of patent pools/cross-licensing with multiple patents that takes place in the shadow of litigation. The model encompasses a wide range of relationships between patents. This includes the two polar cases of perfect substitutes and perfect complements and the whole spectrum between them. The basic presumption in the literature to date, enunciated in the Antitrust Guide Lines for the Licensing and Acquisition of Intellectual Property (1995), is that inclusion of complementary or essential patents in a patent pool is pro-competitive, but assembly of substitute or rival

\footnotetext{
${ }^{9}$ In a companion paper, Lerner, Strojwas, and Tirole (2003) empirically test the theoretical predictions concerning the structure of patent pools by using a sample of 63 pools established between 1895 and 2001 .
} 
patents in a pool can eliminate competition and lead to elevated licensee fees. The model in this paper provides theoretical support for such a presumption, but also provides a few caveats in applying such a policy. In particular, section 3 makes a distinction between ex ante and ex post patent pools, depending on whether patent validity has been established in the court, and derives the optimal patent pool policy. Section 4 extends and checks the robustness of the basic model by considering the possibility that the probability of patents' validity can be correlated. This case arises naturally if the nature of the patent dispute entails the relative priority of patents since one party's validity automatically implies the invalidity of the other patent. Concluding remarks follow in section 5 .

\section{The Model of Patent Pools under Validity Uncertainty}

I consider a situation of multiple patents with dispersed ownership and potentially conflicting claims. For analytical simplicity, I assume that there are two patents, A and B, which are owned by two separate firms. The relationship between these two patents could be either complementary or substitutable. Building on the framework developed by Lerner and Tirole (2004), I present a model that can encompass both perfectly substitutable and perfectly complementary patents and the full range between them. ${ }^{10}$

There is a continuum of potential licensees/users of patents. They are heterogeneous in terms of their willingness to pay for licensing, which is indexed by $\theta$. Patents are assumed to be symmetric in their contributions to licensees' willingness to

\footnotetext{
${ }^{10}$ As emphasized by Lerner and Tirole (2004), patents are rarely perfect complements or perfect substitutes.
} 
pay. More specifically, I assume that licensee type $\theta$ 's gross surplus from using only one and both innovations are given by $v+\theta$ and $V+\theta$, respectively, with $V \geq v .{ }^{11}$ Thus, $\Delta=V-v$ is the incremental value of the second patent and can be interpreted as a parameter representing substitutability/ complementarity of the two patents, with a higher $\Delta$ representing a higher degree of complementarity. For instance, $\Delta=0$ is a case of perfect substitutes since it takes only one technology for the full benefit of $V$, whereas $\Delta$ $=V$ is a case of perfect complements. ${ }^{12}$

I assume that $\theta \in(-\infty, 0]$, with the normalization that $v$ and $V$ represent the willingness to pay for one and two patents for the highest type. Let $F$ denote the cumulative distribution of $\theta$. Then, the demand for the bundle of both patents at royalty rate $R$ can be written as:

$$
Q(R)=\operatorname{Pr}(V+\theta-R \geq 0)=1-F(R-V)
$$

I make the standard assumption that the distribution of types satisfies the monotone hazard rate condition, that is, $F^{\prime} /(1-F)$ is strictly increasing:

\footnotetext{
11 The assumption of additive separability of user preferences is made to simplify the analysis. In particular, it implies that all licensees select the same set of technologies in the market. See Lerner and Tirole (2004) for a more detailed discussion of this assumption.

12 As example of the perfect complementary case would be two patents on technologies that are necessary to make a microprocessor such as one patent on planar technology and the other on the microprocessor bus. In this case, both patents have a stand-alone value of zero and a value of $V$ when used together. An example of symmetric intermediate cases would involve patents on two alternative video standards such as Blu-Ray and HD-DVD. Each can be used alone with a value of $v$. Together, each standard can provide some benefit to the other standard due to indirect network effects, which would raise its value to $V$.
} 


$$
F^{\prime \prime} \cdot(1-F)+\left(F^{\prime}\right)^{2}>0
$$

This assumption ensures that the patent pool's objective function, $R Q(R)$, is quasiconcave and the second order condition for the maximization problem is satisfied:

$$
2 Q^{\prime}(R)+R Q^{\prime \prime}(R)=-2 \cdot F^{\prime}(R-V)-R \cdot F^{\prime \prime}(R-V)<0 . .^{13}
$$

The innovation in this paper is that I treat the intellectual property rights associated with the patents as probabilistic and explicitly consider the uncertainty in the extent of protection a patent provides in the analysis of the incentives to form a patent pool. The uncertainty about the validity of the patents is represented by the parameters $\alpha$ and $\beta \in[0,1]$, which are the probabilities that the court will uphold the validity of patents A and B, respectively, if they are challenged. ${ }^{14}$ I assume a symmetric information structure in that $\alpha$ and $\beta$ are common knowledge.

\section{1. Patent Pools with Ironclad Patents ${ }^{15}$}

As a benchmark, I first analyze a situation in which patent protection is ironclad so the validity of the patents is not an issue. ${ }^{16}$ Without the possibility of patent litigation, let $r_{A}$ and $r_{B}$ denote the royalty rates charged by firm A and firm B, respectively.

13 Using the first order condition, we can rewrite the second order condition as $-2 \cdot F^{\prime}(R-V)-F^{\prime \prime}(R-V) \cdot[1-F(R-V)] / F^{\prime}(R-V)<0$. The second order condition holds if the distribution $F$ satisfies the monotone hazard rate condition. This condition is a standard assumption in the incentive literature and is satisfied by most widely used distributions; See Fudenberg and Tirole (1991, p. 267).

14 With probability $(1-\alpha)(1-\beta)$, for instance, both patents are invalidated. This may be the case if both patents did not reveal the relevant prior art in their applications and were awarded inappropriately.

15 This subsection closely follows Lerner and Tirole (2004) and replicates some of their results. 
As a first step in deriving the Nash equilibrium in the licensing market, consider a hypothetical situation in which licensees are constrained to purchase both patents. Then firm A solves the following problem given firm B's royalty rate $r_{B}$.

$$
\underset{r_{A}}{\operatorname{Max}_{A}} r_{A} \cdot Q\left(r_{A}+r_{B}\right)
$$

The first order condition for firm A's optimal royalty rate $r_{A}$ is given by

$$
Q\left(r_{A}+r_{B}\right)+r_{A} \cdot Q^{\prime}\left(r_{A}+r_{B}\right)=0
$$

which implicitly defines firm A's reaction function $r_{A}=\Theta_{A}\left(r_{B}\right)$. Firm B's reaction

function, $r_{B}=\Theta_{\mathrm{B}}\left(r_{A}\right)$, can be derived in a similar way. The symmetric Nash equilibrium royalty rates $\hat{r}_{A}=\hat{r}_{B}=\hat{r}$ are at the intersection of these two reaction functions. The stability and uniqueness of the Nash equilibrium in the royalty rates are ensured with the monotone hazard assumption of $F .{ }^{17}$ The total royalty rate is given by $\hat{R}=\hat{r}_{A}+\hat{r}_{B}=$ $2 \hat{r}$.

The solution above, however, is predicated on the assumption that potential licensees are not allowed to license only one technology. Thus, we must check whether the equilibrium derived will remain unchanged even if potential licensees are allowed to

\footnotetext{
16 Later I introduce uncertainty about the validity of patents and make a distinction between ex ante and ex post patent pools. Ex ante patent pools are formed when patents considered for patent pools have not yet been contested in the court and thus their validities are uncertain. Ex post patent pools are formed after the validities of patents in consideration have been contested in court and thus there is no uncertainty about their validities. Thus, the patent pools considered in the analysis of this subsection correspond to ex post patent pools.

17 The monotone hazard assumption implies that $Q^{\prime}(R)+R Q^{\prime \prime}(R)<0$.
} 
purchase only one technology. To prevent potential licensees from purchasing only one technology, the following condition should hold:

$$
V-\hat{R} \geq v-\hat{r} \text {, that is, } \Delta \geq \hat{r}
$$

In this case, the demand margin binds for patent holders. ${ }^{18}$ However, if condition (6) is violated, the competitive margin binds. Consequently, potential licensees will purchase only one technology if both firms charge the royalty rate of $\hat{r}$, and the excluded firm will have incentives to cut its price below that of the competitor. Then, the only equilibrium that can be sustained is $r_{A}=r_{B}=\Delta$.

Thus, the equilibrium royalty rate is given by $r *=\min (\Delta, \hat{r})$, with both firms having positive sales.

In contrast, if firms A and B form a patent pool and practice package licensing, the optimal royalty rate is derived by solving

$$
\underset{R}{\operatorname{Max}} R \cdot Q(R)
$$

Let $\widetilde{R}^{*}$ be the optimal royalty rate for the pool. ${ }^{19}$ Then, $\widetilde{R}^{*}$ satisfies the following first order condition:

$$
Q\left(\widetilde{R}^{*}\right)+\widetilde{R}^{*} \cdot Q^{\prime}\left(\widetilde{R}^{*}\right)=0
$$

Proposition 1 shows that with the formation of patent pools, the overall royalty rate for the licensees can be either lower or higher depending on the relationship between the two

\footnotetext{
18 The demand margin binds when an increase in one firm's price induces a reduction of its demand, but not to the exclusion of its technology from users' choice of technologies.

${ }^{19}$ Variables associated with (ex post) patent pools are denoted with a tilde.
} 
technologies; patent pools tend to be procompetitive as patents become more complementary.

Proposition 1 (Lerner-Tirole, 2004). There is a critical level of $\Delta$ such that $R^{*}=r_{A}{ }^{*}+$ $r_{B}^{*}>\widetilde{R} *$ if and only if $\Delta>\Delta *$, where $\Delta *=\widetilde{R} * / 2$. That is, the total royalty rate decreases with the formation of the patent pool if and only if $\Delta>\Delta^{*}=\widetilde{R}^{*} / 2$. In such a case, social incentives and private incentives to form a patent pool are aligned.

Otherwise, patent pools reduce social welfare. ${ }^{20}$

Proof. If $\Delta \geq \hat{r}$ and the demand margin binds, the Nash equilibrium royalty rates $r_{A}{ }^{*}$ $=r_{B}^{*}=\hat{r}$ satisfy

$$
2 Q\left(r_{A}^{*}+r_{B}^{*}\right)+\left(r_{A}^{*}+r_{B}^{*}\right) \cdot Q^{\prime}\left(r_{A}^{*}+r_{B}^{*}\right)=0
$$

Evaluating the first order condition for the patent pool (8) at $R^{*}=r_{A} *+r_{B} *$ yields

$$
Q\left(r_{A}^{*}+r_{B}^{*}\right)+\left(r_{A}^{*}+r_{B}^{*}\right) \cdot Q^{\prime}\left(r_{A}^{*}+r_{B}^{*}\right)=-Q\left(r_{A}^{*}+r_{B} *\right)<0
$$

This implies that $R^{*}=r_{A}^{*}+r_{B}^{*}=2 \hat{r}>\widetilde{R} *$.

If $\Delta<\hat{r}$ and the competitive margin binds, the Nash equilibrium royalty rates $r_{\mathrm{A}}{ }^{*}$ $=r_{B}{ }^{*}=\Delta$, with $R^{*}=2 \Delta$. Since $2 \hat{r}>\widetilde{R}^{*}$, we have the desired result that that $R^{*}=r_{A}{ }^{*}$ $+r_{B}^{*}=2 \Delta>\widetilde{R}^{*}$ if and only if $\Delta>\Delta *=\widetilde{R} * / 2$. See also Figure 1. Q.E.D

\footnotetext{
20 The analysis of patent pooling implicitly assumes that the two members of the pool are not permitted to issue licenses for their own patents independently of the package license for both patents from the pool. Some patent pools explicitly allow this independent licensing. If members of the pool can and do license independently, then the pool cannot lower welfare. See Lerner and Tirole (2004) for more details.
} 

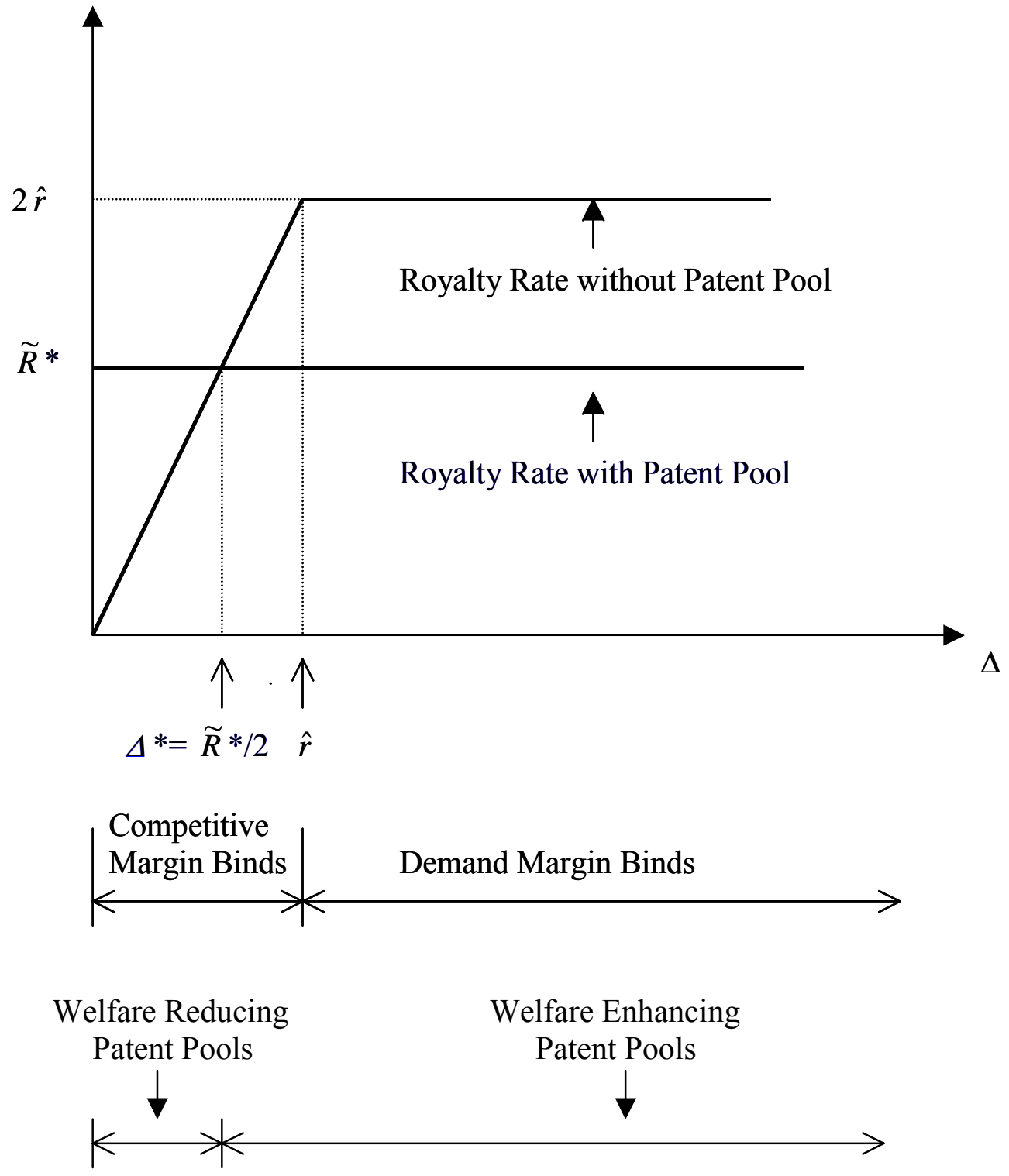

\section{Figure 1. Patent Pools with Ironclad Patents}

As an example, consider a case where $\theta$ is uniformly distributed between minus infinity and zero with population density of one. This generates a linear demand curve for licensing, $Q(R)=V-R$. It can be easily verified that the optimal royalty rate for the patent pool, $\widetilde{R}^{*}$, is given by $V / 2$ in this case. Without a patent pool, the competitive 
margin binds and the symmetric equilibrium royalty rate is given by $r^{*}=\Delta$, if $\Delta<V / 3$. Otherwise, the demand margin binds and the equilibrium royalty rate is given by $r^{*}=$ $V / 3$. The critical value of $\Delta$ is given by $\Delta^{*}=V / 4$.

The result that patent pools can be welfare enhancing when technologies become more complementary and the demand margin binds is a generalization of the well-known result that dates back to Cournot's (1927) analysis of the complementary monopoly problem. When the demand margin binds, without coordination in pricing each patentee does not internalize the increase in the other patentee's profits when the demand for the package is increased by a reduction in its price. Thus, a patent pool can decrease the overall royalty rates for the package and simultaneously increase both patentees' profits and consumer surplus. Consequently, social welfare also increases. As a result an argument can be made for lenient treatment of a patent pool due to its pro-competitive effects with complementary patents. In the next subsection, however, I consider the case where patent protection is not perfect. In this case, I show that more caution is needed in granting blanket immunity even towards patent pools comprised of complementary patents, especially when weak patents are involved.

\section{2. Uncertain Patents and Litigation Incentives in the Absence of Patent Pools}

To investigate implications of uncertain patents, I now consider the possibility that the scope of the patent is not exact and that the validity itself can be challenged. Let me analyze each firm's incentives to challenge the validity of the other firm's patent. If one firm, say A, challenges firm B's patent, it is assumed that it is optimal for firm B to counterattack by challenging the validity of firm A's patent. This assumption will hold 
if there are economies of scope in litigations since the counter-suit will not significantly add to the cost of litigation beyond that of defending its own patent. In fact, in litigation cases where the accused also has patents, the accused party invariably lodges a countersuit against the challengers. This assumption implies that attacking another firm's patent validity or infringement creates a risk of having one's own patent invalidated in the process. For instance, when Hewlett-Packard recently sued data storage company EMC Corp. for infringing some of its patents, EMC countersued H-P with its own patent infringement claims. ${ }^{21}$

I assume that the probability of validity of each patent is independent of the other. This would be an appropriate assumption with complementary patents or if the technologies of the two patents were developed by taking completely different research approaches in the case of substitute patents. As an example, consider a gene therapy product to treat a disease. There are two alternative methods developed to get genes into cells. Sandoz developed the ex vivo process in which cells are removed form the body, the genetic material is inserted, and the cells are returned to the body. Ciba Geigy, in contrast, developed the in vivo process in which the genetic material is inserted while the

\footnotetext{
${ }^{21}$ Another example is the recent patent dispute between Nikon and ASML involving lithography equipment, which is used to print circuits on silicon wafers that become semiconductors or chips. When Nikon filed a complaint against ASML claiming the Dutch company infringed on seven Nikon patents, ASML responded by claiming that the respective Nikon patents in question were invalid, and a counterclaim was filed alleging that Nikon infringed on four ASML patents (see Chappell, 2002).
} 
cells remain in the body. Therefore, it would be a reasonable assumption that the probability of validity of each patent is independent of the other. ${ }^{22}$

One issue to consider in my analysis is if the firms in patent disputes have legal "standing to sue." This issue does not arise for substitute patents. For complementary patents, one natural way to interpret the situation is to consider a case of potentially "blocking" patents. For instance, technology A is a broad patent on a basic research tool whose commercial value is zero in itself. Technology B is an application of technology A that enables commercialization of the latter with a value of $V$. Thus, B is a subservient patent which cannot be practiced without a license from the holder of patent A if B is found to infringe on patent $A$. In such a scenario, we have a case of perfect complementarity: the value of each patent alone is zero $(v=0)$ whereas they generate the value of $\mathrm{V}$ taken together $(\Delta=V)$. Such a blocking relationship may confer the patentholder A standing to sue B (or the users of technology B if they do not pay for A, for that matter). Once A lodges a patent suit against B, the optimal response of B is to invalidate patent A. ${ }^{23}$

\footnotetext{
${ }^{22}$ In the next section, I consider the case where disputes are mainly on the issue of priority and one party's validity means the other party's patent being revoked.

${ }^{23}$ Our main results on the lack of incentives to litigate would not change even if we assume only the users who license both patents have standing to sue. When a user challenges and invalidates a patent, the entire cost of litigation is borne by the challenger, but the benefits of invalidation could accrue to all users. This is due to the Supreme Court's 1971 decision in Blonder-Tongue that if a challenger successfully invalidates a patent, other potential infringers of the patent can rely on this and need not pay royalties (Blonder-Tongue Laboratories, Inc. v. University of Illinois Foundation, 402 U.S. 313 (1971)). The free-riding problem created by Blonder-Tongue could limit the incentives for a user to invalidate weak patents. This also
} 
Let $\Pi^{\mathrm{M}}$ and $\Pi^{\mathrm{D}}$, respectively, denote the patent-holder's profits when it is the only firm who has a patent and when it is one of the two firms who have patents. Notice that both profits depend on $\Delta$. If a firm is the only patent holder after the other patent is invalidated and now freely available, potential licensees will buy the technology if and only if

$$
V+\theta-r>\max [v+\theta, 0]
$$

Thus, the demand for the monopolistic supplier of the patent is given by:

$$
q^{M}(r)= \begin{cases}Q(r), & \text { if } r \leq \Delta \\ 0, & \text { if } r>\Delta\end{cases}
$$

This implies that the pricing decision for the monopolistic supplier of the patent is constrained by the existence of the other freely available technology if $\Delta<\widetilde{R}^{*}$. The optimal price for the monopolist is given by:

$$
r^{M}=\left\{\begin{array}{l}
\Delta, \text { if } \Delta<\tilde{R}^{*} \\
\tilde{R}^{*}, \text { if } \Delta \geq \tilde{R}^{*}
\end{array}\right.
$$

The profit for the monopolistic supplier of the patent is given by:

$$
\Pi^{M}= \begin{cases}\Delta Q(\Delta), & \text { if } \Delta<\tilde{R}^{*} \\ \tilde{R}^{*} Q\left(\tilde{R}^{*}\right), & \text { if } \Delta \geq \tilde{R}^{*}\end{cases}
$$

If both firms hold a patent,

implies that the distortion identified in this paper would increase if we have more patentees in the model. I thank an anonymous referee for this observation. See also Farrell and Shapiro (2008) and Choi (1998). 


$$
\Pi^{D}=r^{*} \cdot Q\left(2 r^{*}\right)= \begin{cases}\Delta Q(2 \Delta), & \text { if } \Delta<\hat{r} \\ \hat{r} Q(2 \hat{r}), & \text { if } \Delta \geq \hat{r}\end{cases}
$$

It can be easily verified that $\Pi^{\mathrm{M}}>\Pi^{\mathrm{D}}$ for all values of $\Delta \in[0, \mathrm{~V}] . \quad$ Let the legal costs of litigation be denoted by $\chi$, which are assumed to be the same for both firms.

Each firm's profits without litigation are given by:

$$
V_{A}^{N L}=V_{B}^{N L}=\Pi^{\mathrm{D}}
$$

If there is litigation concerning the validity of the patents, each firm's profits are given by

$$
V_{A}^{L}=\alpha\left[\beta \Pi^{\mathrm{D}}+(1-\beta) \Pi^{\mathrm{M}}\right]-\chi, V_{B}^{L}=\beta\left[\alpha \Pi^{\mathrm{D}}+(1-\alpha) \Pi^{\mathrm{M}}\right]-\chi
$$

Firm A will have an incentive to litigate if

$$
\Lambda_{A}=V_{A}^{L}-V_{A}^{N L}=\left\{\alpha\left[\beta \Pi^{\mathrm{D}}+(1-\beta) \Pi^{\mathrm{M}}\right]-\chi\right\}-\Pi^{\mathrm{D}} \geq 0
$$

It can be easily verified that

$$
\begin{aligned}
& \frac{\partial \Lambda_{A}}{\partial \alpha}=\beta \Pi^{\mathrm{D}}+(1-\beta) \Pi^{\mathrm{M}}>0 \\
& \frac{\partial \Lambda_{A}}{\partial \beta}=\alpha\left[\Pi^{\mathrm{D}}-\Pi^{\mathrm{M}}\right]<0 .
\end{aligned}
$$

Thus, firm A's incentives to litigate increase with the strength of its own patent and decrease with the strength of the other firm's patent. Given the other firm's patent strength, $\beta$, firm A will litigate if

$$
\alpha \geq \psi_{\mathrm{A}}(\beta)=\frac{\Pi^{D}+\chi}{\beta \Pi^{D}+(1-\beta) \Pi^{M}}
$$

It can be easily verified that $\psi_{\mathrm{A}}(\beta)$ is upward sloping and convex in $\beta$.

Similarly, firm B will have incentive to litigate if 


$$
\Lambda_{B}=V_{B}^{L}-V_{B}^{N L}=\left\{\beta\left[\alpha \Pi^{\mathrm{D}}+(1-\alpha) \Pi^{\mathrm{M}}\right]-\chi\right\}-\Pi^{\mathrm{D}} \geq 0
$$

Given the strength of firm A's patent, $\alpha$, firm B will initiate litigation if

$$
\beta>\psi_{\mathrm{B}}(\alpha)=\frac{\Pi^{D}+\chi}{\alpha \Pi^{D}+(1-\alpha) \Pi^{M}}
$$

Let $\mathcal{L}_{\mathrm{A}}$ and $\mathcal{L}_{\mathrm{B}}$ denote the set of $(\alpha, \beta)$ that satisfies conditions (10) and (12), respectively, i.e.,

$$
\begin{aligned}
& \mathcal{L}_{\mathrm{A}}=\left\{(\alpha, \beta) \in[0,1]^{2} \mid \alpha\left[\beta \Pi^{\mathrm{D}}+(1-\beta) \Pi^{\mathrm{M}}\right]-\chi>\Pi^{\mathrm{D}}\right\} \\
& \mathcal{L}_{\mathrm{B}}=\left\{(\alpha, \beta) \in[0,1]^{2} \mid \beta\left[\alpha \Pi^{\mathrm{D}}+(1-\alpha) \Pi^{\mathrm{M}}\right]-\chi>\Pi^{\mathrm{D}}\right\}
\end{aligned}
$$

Litigation will take place if either firm has an incentive to litigate, i.e., $(\alpha, \beta) \in \mathcal{L}$, where $\mathcal{L}$ $=\mathcal{L}_{\mathrm{A}} \cup \mathcal{L}_{\mathrm{B}}$. There will be no litigation only when neither firm has any incentive to litigate. This is when $\alpha$ and $\beta$ are low, that is, both firms have weak patents and $(\alpha, \beta) \in \mathcal{N} \mathcal{L}$, where $\mathcal{N} \mathcal{L}=\mathcal{L}^{\mathrm{C}}=[0,1]^{2}-\mathcal{L}$.

Now let me analyze social incentives to litigate. Let $C S(R)$ be the level of consumer/user surplus when the royalty rate for the bundle of both patents is given by $R$, where $C S(R)=\int_{R}^{V} Q(p) d p=\int_{R}^{V}[1-F(p-V)] d p$ and $C S^{\prime}(R)<0$. If there is litigation, the downstream market price depends on the outcome of the litigation. For instance, if the outcome of litigation is that both patents are invalidated, both technologies are freely available at the royalty rate of zero. Instead, if both patents are deemed valid, the royalty rate would be $R^{*}=r_{A}{ }^{*}+r_{B}{ }^{*}$ as in the case of no litigation. If only one of them is deemed valid, the holder of the valid patent will set the royalty rate at $r^{M}=\Delta$ if $\Delta<\tilde{R}^{*}$ and $r^{M}=\tilde{R}^{*}$ if $\Delta \geq \tilde{R}^{*}$. 
Let me follow the standard practice of using the sum of consumer surplus and industry profits as a measure of social welfare. Let $\mathrm{W}^{\mathrm{M}}, \mathrm{W}^{\mathrm{D}}$ and $\mathrm{W}^{\mathrm{C}}$ denote the welfare levels when the (upstream) market structures are monopoly (i.e., only one patent is deemed valid), duopoly (both patents are valid), and perfectly competitive (both patents are invalidated), respectively.

$$
\begin{aligned}
& \mathrm{W}^{\mathrm{M}}=\Pi^{M}+C S\left(r^{M}\right)= \begin{cases}\Delta Q(\Delta)+C S(\Delta), & \text { if } \Delta<\tilde{R}^{*} \\
\tilde{R}^{*} Q\left(\tilde{R}^{*}\right)+C S\left(\tilde{R}^{*}\right), & \text { if } \Delta \geq \tilde{R}^{*}\end{cases} \\
& \mathrm{W}^{\mathrm{D}}=2 \Pi^{\mathrm{D}}+C S\left(R^{*}\right)= \begin{cases}2 \Delta Q(2 \Delta)+C S(2 \Delta), & \text { if } \Delta<\hat{r} \\
2 \hat{r} Q(2 \hat{r})+C S(2 \hat{r}), & \text { if } \Delta \geq \hat{r}\end{cases} \\
& \mathrm{W}^{\mathrm{C}}=C S(0)
\end{aligned}
$$

We have $\mathrm{W}^{\mathrm{D}}<\mathrm{W}^{\mathrm{M}}<\mathrm{W}^{\mathrm{C}}$ since $\hat{r}<\widetilde{R} *<2 \hat{r}$. That is, social welfare increases as more patents are invalidated and become freely available.

Without a patent pool, the expected social welfare associated with litigation is given by

$$
S W^{L}=\left[\alpha \beta W^{\mathrm{D}}+(\alpha-2 \alpha \beta+\beta) \mathrm{W}^{\mathrm{M}}+(1-\alpha)(1-\beta) \mathrm{W}^{\mathrm{C}}\right]-2 \chi
$$

If there is no litigation and no patent pool, the market price at the downstream stage is $R^{*}=r_{A}^{*}+r_{B} *$. Social welfare without litigation is then given by

$$
S W^{N L}=\mathrm{W}^{\mathrm{D}}=2 \Pi^{\mathrm{D}}+\mathrm{CS}\left(R^{*}\right)
$$

Therefore, the social incentive to litigate is given by

$$
\Lambda_{S}=S W^{L}-S W^{N L}=(1-\alpha \beta)\left[\mathrm{W}^{\mathrm{M}}-\mathrm{W}^{\mathrm{D}}\right]+(1-\alpha)(1-\beta)\left[\mathrm{W}^{\mathrm{C}}-\mathrm{W}^{\mathrm{M}}\right]-2 \chi
$$

It is not expected that private incentives to litigate would coincide with social incentives. In particular, if the cost of litigation $(\chi)$ is relatively low $\Lambda_{S}>0$, and patent disputes 
through litigation are socially beneficial since they can lead to invalidation of patents and less market power. This implies that when both patents are weak the private and social incentives will always diverge since $\lim _{\substack{\alpha \rightarrow 0 \\ \beta \rightarrow 0}} \Lambda_{A}=\lim _{\substack{\alpha \rightarrow 0 \\ \beta \rightarrow 0}} \Lambda_{B}=-\Pi^{\mathrm{D}}<0$. We can conclude that when patents are weak, there will be a serious lack of incentives to litigate among patent-holders since they accommodate each other by adopitng the policy of "live and let live."

\subsection{Patent Pools in the Presence of Uncertain Patents}

The analysis in the previous subsection applies to the case where the formation of a patent pool is not allowed, say, due to restrictions by antitrust authorities. If the formation of a patent pool is allowed without any restrictions, the only role of litigation is to set "threat points" for negotiating licenses. The terms of patent pools are negotiated in the shadow of what would happen otherwise, and in this way the expectation of litigation outcomes determines how the royalties are shared between pool members.

Let me analyze the private incentives to form a patent pool and how royalty income is divided between the two firms. I assume that the surplus from negotiation is equally split between the two firms as in Green and Scotchmer (1995). When the parameters $(\alpha, \beta)$ belong to the set $\mathcal{N} \mathcal{L}$, such that both firms have no incentive to litigate, both will get the same royalty rate $\widetilde{R} * / 2$ regardless of their relative patent strengths. When $(\alpha, \beta) \in \mathcal{L}$, there will be litigation in the absence of a patent pool. In this case, the division of the royalty income reflects the relative strength of the patents. Let $\kappa$ and 
$(1-\kappa)$ denote the proportions of the royalty income that accrue to firm A and B, respectively. Then, the bargaining solution with equal surplus implies that

$$
\kappa \Pi^{\mathrm{M}}-\left\{\alpha\left[\beta \Pi^{\mathrm{D}}+(1-\beta) \Pi^{\mathrm{M}}\right]-\chi\right\}=(1-\kappa) \Pi^{\mathrm{M}}-\left\{\beta\left[\alpha \Pi^{\mathrm{D}}+(1-\alpha) \Pi^{\mathrm{M}}\right]-\chi\right\} .
$$

This yields $\kappa=\frac{1+\alpha-\beta}{2}$.

Proposition 2. Under bargaining with equal surplus, the royalty rates are the same for both firms at $\widetilde{R}^{*} / 2$ when both firms have weak patents, that is, $(\alpha, \beta) \in \mathcal{N} \mathcal{L}$. If $(\alpha, \beta) \in \mathcal{L}$ and at least one of the firms has incentives to litigate, the royalty rates reflect the relative strength of the patents (i.e., the probability of patent's validity) in the pool.

Example. Once again, consider a case where $\theta$ is uniformly distributed between minus infinity and zero with density one, which generates a linear demand curve for licensing, $Q(P)=V-P$. Assume that $\Delta=V / 2$. In this case, the profits for the monopoly and duopoly are given by $\Pi \mathrm{M}=\frac{V^{2}}{4}$ and $\Pi \mathrm{D}=\frac{V^{2}}{9}$, respectively. For simplicity, assume that the cost of litigation is negligible with $\chi=0$. Suppose that $\beta=1 / 5$. Then, it can be easily verified that firm B has no incentive to initiate litigation, and firm A will have an incentive to litigate if and only if $\alpha \geq 1 / 2$. Thus, firm A and B will share the monopoly profit equally and the division of royalty income is invariant in $\alpha$ as long as $\alpha<1 / 2$. However, if $\alpha \geq 1 / 2$ the division of royalties reflects the relative strength of the two patents. As can be seen in Figure 2, the value of patents can be discontinuous in patent strength at the point of regime change. 


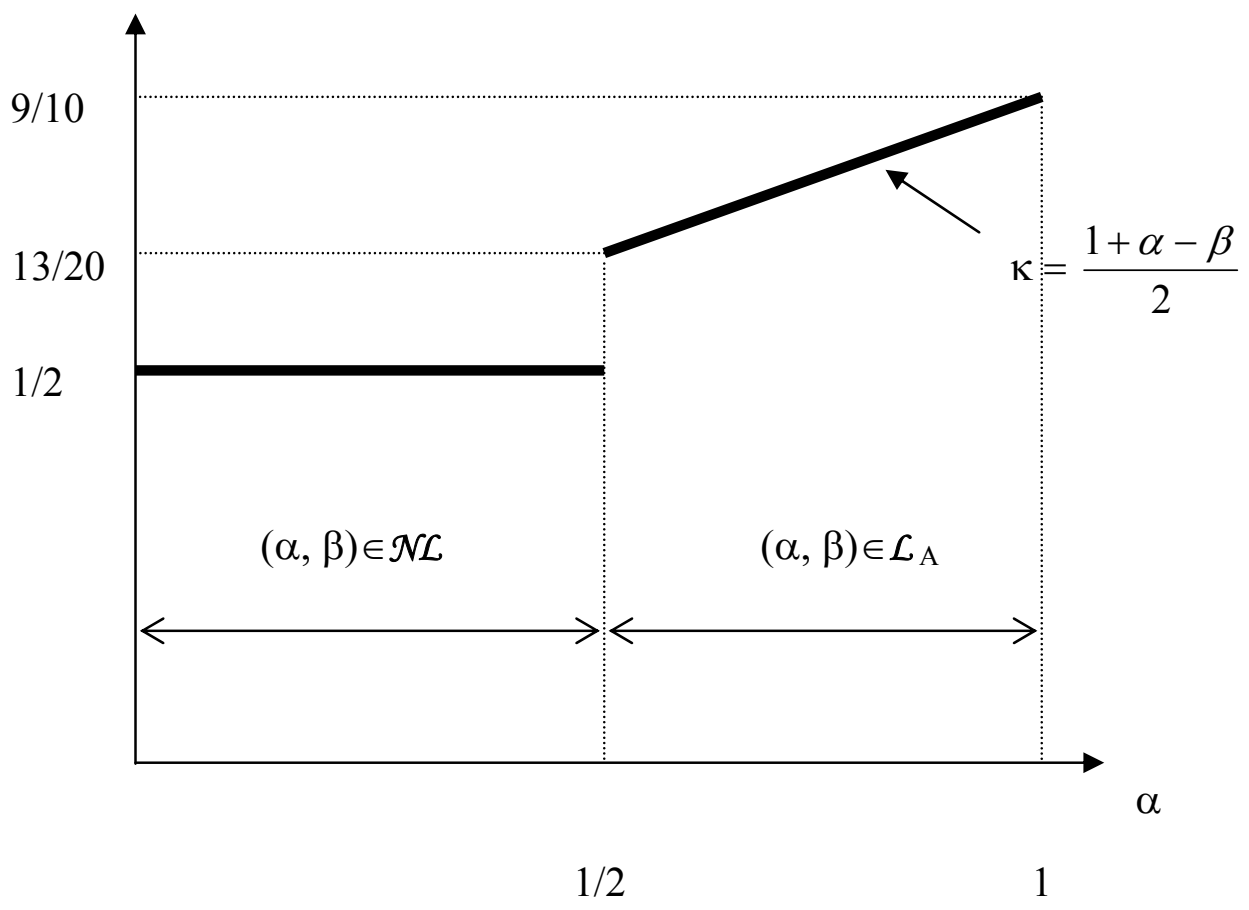

Figure 2: Firm A's Share of Royalty Income as a function of $\alpha$ with $\beta=1 / 5$

In a model of patent dispute, Shapiro (2003) also points out the possibility that the value of a patent is not linear in patent strength when settlement is possible. However, the reason for non-linearity is completely different. He considers a patent dispute between the incumbent who holds a patent and the entrant who challenges it. Thus, there is only one patent involved in the dispute. More importantly, his paper does not analyze the incentives to litigate in the first place. The value of a patent is always continuous and increasing in patent strength even though it is non-linear. My model indicates that the consideration of litigation incentives introduces a discontinuity in the division of royalty incomes. 


\section{Optimal Antitrust Policy on Patent Pools}

I now consider the optimal antitrust policy concerning patent pools in a situation where the social planner's only decision is whether to approve patent pools or not. With probabilistic patent rights, I need to make a distinction between ex ante and ex post policy, depending on the information available at the time of the policy decision. Ex ante policy decisions are the ones made when patents considered for patent pools have not yet been contested in the court and thus their validities are uncertain. In contrast, ex post policy decisions are the ones made after the validities of patents in consideration have been contested in court and thus there is no uncertainty about their validities. ${ }^{24}$ I will call patent pools formed before a patent validity check in court ex ante patent pools. Patent pools formed after litigation are called ex post patent pools.

\section{1. Ex Post Optimal Patent Pool Policy}

Once patents in consideration are contested in court, they are either held valid or invalidated, eliminating any uncertainty about their validities. It is obvious that the ex post optimal patent pool policy requires that no invalidated patents be included in the pool. Thus, the only relevant case to consider is the one in which both patents are held valid. Notice that this case is equivalent to the case of ironclad patents we analyzed earlier. Since ex post decisions are made with respect to ironclad patents, the analysis of

\footnotetext{
24 There is no presumption here that litigation delivers the right answer concerning the validity of patents disputed. Courts will certainly make errors and cannot be perfect in their verdicts. However, all that is required for the main results of this paper is that litigation eliminates uncertainty about the validity of patents. If we also consider the incentives to innovate for patents, potential errors by the courts would matter and should be taken into account.
} 
subsection II.1 applies. That is, the optimal ex post patent pool policy is to allow patent pools if and only if $\Delta>\Delta *$, where $\Delta *=\widetilde{R} * / 2$ (see Proposition 1$)$.

This implies that with the optimal ex post patent policy in place, each firm's ex post profit and social welfare when both patents are found to be valid are respectively given by:

$$
\begin{aligned}
& \tilde{\Pi}^{D}= \begin{cases}\Pi^{D}=r^{*} \cdot Q\left(2 r^{*}\right)=\Delta Q(2 \Delta), & \text { if } \Delta<\Delta^{*}=\frac{R^{*}}{2}(<\hat{r}) \\
\frac{\tilde{R}^{*} Q\left(\tilde{R}^{*}\right)}{2}, & \text { if } \Delta \geq \Delta^{*}\end{cases} \\
& \tilde{W}^{D}= \begin{cases}W^{D}=2 \Pi^{D}+C S\left(R^{*}\right)=2 \Delta Q(2 \Delta)+C S(2 \Delta), & \text { if } \Delta<\Delta^{*} \\
\tilde{R}^{*} Q\left(\tilde{R}^{*}\right)+C S\left(\tilde{R}^{*}\right), & \text { if } \Delta \geq \Delta^{*}\end{cases}
\end{aligned}
$$

\section{2. Ex Ante Optimal Patent Pool Policy}

Now I turn my attention to ex ante optimal policy. Obviously, the analysis of ex ante policy depends crucially on a counterfactual analysis of what would happen in the market if the patent pool is not approved. In particular, it depends on if any firm would have an incentive to litigate in the absence of ex ante patent pools, which in turn depends on ex post patent pool policy, i.e., what is allowed if both firms' patents are validated. I assume that ex post patent policy is optimal; that is, a patent pool is allowed ex post if and only if both patents are upheld to be valid and $\Delta>\Delta * .25$

\footnotetext{
${ }^{25}$ In the previous version of the paper, I assumed no ex post patent pool and derived qualitatively the same results. See Choi (2003) for more details.
} 
To analyze the social incentives to form ex ante patent pools, I need to consider firms' incentives to litigate in the absence of an ex ante patent pool. By proceeding as in subsection II.2, I can easily derive the condition for firm A to litigate as

$$
(10)^{\prime} \quad \alpha \geq \tilde{\Psi}_{A}(\beta)=\frac{\Pi^{D}+\chi}{\beta \tilde{\Pi}^{D}+(1-\beta) \Pi^{M}},
$$

where a tilde above variables signifies that ex post optimal patent policy is reflected in the litigation decision. Similarly, firm B will initiate litigation if

$$
(12)^{\prime} \quad \beta \geq \tilde{\Psi}_{B}(\alpha)=\frac{\Pi^{D}+\chi}{\alpha \tilde{\Pi}^{D}+(1-\alpha) \Pi^{M}}
$$

Let $\tilde{\mathcal{L}}_{\mathrm{A}}$ and $\tilde{\mathcal{L}}_{\mathrm{B}}$ denote the set of $(\alpha, \beta)$ that satisfies conditions $(10)^{\prime}$ and $(12)^{\prime}$, respectively, i.e.,

$$
\begin{aligned}
& \tilde{\mathcal{L}}_{\mathrm{A}}=\left\{(\alpha, \beta) \in[0,1]^{2} \mid \alpha\left[\beta \tilde{\Pi}^{D}+(1-\beta) \Pi^{\mathrm{M}}\right]-\chi>\Pi^{\mathrm{D}}\right\} \\
& \tilde{\mathcal{L}}_{\mathrm{B}}=\left\{(\alpha, \beta) \in[0,1]^{2} \mid \beta\left[\alpha \tilde{\Pi}^{D}+(1-\alpha) \Pi^{\mathrm{M}}\right]-\chi>\Pi^{\mathrm{D}}\right\}
\end{aligned}
$$

Once again, litigation will take place if either firm has an incentive to litigate, i.e., $(\alpha, \beta) \in \tilde{\mathcal{L}}$, where $\tilde{\mathcal{L}}=\tilde{\mathcal{L}}_{\mathrm{A}} \cup \tilde{\mathcal{L}}_{\mathrm{B}}$.

I consider two cases to analyze the social incentives to form ex ante patent pools.

\section{Case $1 .(\alpha, \beta) \in \tilde{L}$}

In this case, if the ex ante patent pool is not allowed there will be patent litigation challenging the validity of each other's patent. Let $\widetilde{S W}$ denote the level of social welfare that prevails with the formation of an ex ante patent pool. With a patent pool, the royalty rate for the bundle of both technologies is given by $\widetilde{R}^{*}$, regardless of $\Delta$. This implies that $\widetilde{S W}=\tilde{W}^{M}$, where $\tilde{W}^{M}=\tilde{R}^{*} Q\left(\tilde{R}^{*}\right)+C S\left(\tilde{R}^{*}\right)$. 
Therefore, ex ante patent pools should be allowed if

$$
\begin{aligned}
\widetilde{S W}-S W^{L} & =\tilde{W}^{M}-\left\{\left[\alpha \beta \tilde{W}^{D}+(\alpha-2 \alpha \beta+\beta) \mathrm{W}^{\mathrm{M}}+(1-\alpha)(1-\beta) \mathrm{W}^{\mathrm{C}}\right]-2 \chi\right\} \\
& =\alpha \beta\left[\mathrm{W}^{\mathrm{M}}-\tilde{W}^{D}\right]-(1-\alpha)(1-\beta)\left[\mathrm{W}^{\mathrm{C}}-\mathrm{W}^{\mathrm{M}}\right]+\left[\tilde{W}^{M}-\mathrm{W}^{\mathrm{M}}\right]+2 \chi>0
\end{aligned}
$$

Lemma. If the patent policy is ex post optimal and the litigation cost is negligible (i.e., $\chi \approx 0$ ), ex ante patent pools should not be allowed.

Proof. I prove this by showing that condition (19) can never be satisfied if $\chi \approx 0$. To demonstrate this, I consider three sub-cases depending on the magnitude of $\Delta$.

(i) $\Delta<\widetilde{R} * / 2(<\hat{r})$

With a negligible litigation cost, condition (19) can be rewritten as:

$$
\beta>\frac{\left[W^{M}-\tilde{W}^{M}\right]+(1-\alpha)\left[W^{C}-W^{M}\right]}{\alpha\left[W^{M}-\tilde{W}^{D}\right]+(1-\alpha)\left[W^{C}-W^{M}\right]}
$$

Notice that we have $\mathrm{W}^{\mathrm{C}}>\mathrm{W}^{\mathrm{M}}>\tilde{W}^{D}=W^{D}>\tilde{W}^{M}$ for $\Delta<\widetilde{R} * / 2$. Therefore, the RHS of inequality (20) is larger than 1 . As a result, condition (20) cannot be satisfied. This implies that if the two technologies are very close substitutes (more precisely, if $\Delta<\widetilde{R} * / 2$ ), patent pools should never be allowed. The reason is that even in the worst possible scenario under litigation, which is both patents being held valid, social welfare is still higher than when under an ex ante patent pool. This result is consistent with the conventional wisdom that patent pools should not be allowed for close substitutes.

(ii) $\widetilde{R} * / 2<\Delta<\widetilde{R} *$

In this case, we have $\mathrm{W}^{\mathrm{C}}>\mathrm{W}^{\mathrm{M}}>\tilde{W}^{D}=\tilde{W}^{M}>W^{D}$. Therefore, with $\chi \approx 0$,

$$
\widetilde{S W}-S W^{L} \approx-(1-\alpha \beta)\left[\mathrm{W}^{\mathrm{M}}-\tilde{W}^{D}\right]-(1-\alpha)(1-\beta)\left[\mathrm{W}^{\mathrm{C}}-\mathrm{W}^{\mathrm{M}}\right]<0 .
$$


(iii) $\Delta \geq \widetilde{R} *$

For $\Delta \geq \widetilde{R}^{*}$, we have $\mathrm{W}^{\mathrm{C}}>\mathrm{W}^{\mathrm{M}}=\tilde{W}^{M}=\tilde{W}^{D}$. This implies that with $\chi \approx 0$,

$$
\widetilde{S W}-S W^{L} \approx-(1-\alpha)(1-\beta)\left[\mathrm{W}^{\mathrm{C}}-\mathrm{W}^{\mathrm{M}}\right]<0 .
$$

Sub-cases of (ii) and (iii) indicate that ex ante patent pools should not be allowed even if the two technologies are complementary (more precisely, even if $\Delta>\widetilde{R}^{*} / 2$ ) as long as the litigation costs are negligible. In other words, patent pools should be allowed only after the validities of all patents are certified in courts and they are sufficiently complementary (i.e., $\Delta>\widetilde{R} * / 2$ ). ${ }^{26}$ Thus, provided that the ex post optimal patent pool policy is in place, the only way to justify ex ante patent pools is significant litigation costs.

\section{Case 2. $(\alpha, \beta) \in \widetilde{\mathcal{N} \mathcal{L}}$}

In this case, if the ex ante patent pool is not allowed, there will be no patent litigation, assuming that the ex post patent policy is optimal. Since no one has any incentive to litigate to invalidate each other's patent, the situation is as if all patents were ironclad. Thus, policy concerning patent pools should be the same as that under ironclad patents analyzed before. The social welfare without a patent pool is given by $S W^{N L}=$

\footnotetext{
26 The previous version of the paper (Choi, 2003) considers a more limited patent pool policy in which the patent pool decision cannot be contingent on the outcome of patent litigation and is made only at the ex ante stage. In such a case, there are cases in which ex ante patent pool should be allowed. In particular, with the linear demand example considered earlier, I show that if $\Delta \geq V / 2$, patent pools should be allowed when $\beta \geq \frac{1-\alpha}{1-\frac{2}{9} \alpha}$.
} 
$\mathrm{W}^{\mathrm{D}}=2 \Pi^{\mathrm{D}}+C S\left(R^{*}\right)$ whereas the social welfare with a patent pool is $\tilde{W}^{M}$. This implies that patent pools should be allowed in this case if $\Delta>\Delta^{*}=\widetilde{R} * / 2$ (see Proposition 1).

The following proposition summarizes the optimal patent pool policy.

Proposition 3. If $(\alpha, \beta) \in \tilde{L}$ and the litigation cost is negligible, ex ante patent pools should not be allowed. Ex post litigation, patent pools should be allowed only if both patents are found to be valid and $\Delta>\Delta^{*}$. If $(\alpha, \beta) \in \widetilde{\mathcal{N L}}$, ex ante patent pools should be allowed if $\Delta>\Delta^{*}$.

To be more concrete, let me again consider a specific example of uniform distribution which yields a liner demand for the bundle of the two technologies, $Q(P)=V$ $-P$. Here, firms A and B will set the royalty rate of $r_{A}{ }^{*}=r_{B}{ }^{*}=\Delta$ if $\Delta<V / 3$, and $r_{A}{ }^{*}$ $=r_{B} *=V / 3$ if $\Delta \geq V / 3$. If one of the patents is invalidated, the other patent-holder as a monopolist sets the royalty rate of $r^{M}=\Delta$ if $\Delta<V / 2$, and $r^{M}=V / 2$ if $\Delta \geq V / 2$. The optimal royalty rate under a patent pool is given by $\widetilde{R}^{*}=V / 2$. The critical value $\Delta^{*}$ is $V / 4$. This leads to

$$
\begin{aligned}
& \Pi^{M}=\left\{\begin{array}{ll}
\Delta(1-\Delta), & \text { if } \Delta<V / 2 \\
V^{2} / 4, & \text { if } \Delta \geq V / 2
\end{array} \quad \Pi^{D}= \begin{cases}\Delta(V-2 \Delta), & \text { if } \Delta<V / 3 \\
V^{2} / 9, & \text { if } \Delta \geq V / 3\end{cases} \right. \\
& \tilde{\Pi}^{D}= \begin{cases}\Delta(V-2 \Delta), & \text { if } \Delta<V / 4 \\
V^{2} / 8, & \text { if } \Delta \geq V / 4\end{cases} \\
& \mathrm{W}^{\mathrm{M}}=\Pi^{M}+C S\left(r^{M}\right)= \begin{cases}\frac{V^{2}}{2}-\frac{\Delta^{2}}{2}, & \text { if } \Delta<V / 2 \\
3 V^{2} / 8, & \text { if } \Delta \geq V / 2\end{cases}
\end{aligned}
$$




$$
\begin{aligned}
& \mathrm{W}^{\mathrm{C}}=C S(0)=V^{2} / 2 \\
& \tilde{W}^{M}=\tilde{R} * Q\left(\tilde{R}^{*}\right)+C S\left(\tilde{R}^{*}\right)=3 V^{2} / 8 \\
& \tilde{W}^{D}= \begin{cases}W^{D}=2 \Pi^{D}+C S\left(R^{*}\right)=\frac{V^{2}}{2}-2 \Delta^{2}, & \text { if } \Delta<V / 4 \\
\tilde{R}^{*} Q\left(\tilde{R}^{*}\right)+C S\left(\tilde{R}^{*}\right)=3 V^{2} / 8, & \text { if } \Delta \geq V / 4\end{cases}
\end{aligned}
$$

To demonstrate the divergence in social and private incentives to form ex ante patent pools, consider the case where $\Delta \geq V / 2$. In this case, it easily be shown that litigation takes place with negligible litigation costs if $\beta \geq \frac{8}{9-2 \alpha}$ or $\alpha \geq \frac{8}{9-2 \beta}$ holds. The areas of incongruence between the social and private incentives are represented as dotted ones in Figure 3. In the dotted areas, social welfare increases with litigation and one of the two firms will have incentives to litigate if patent pools are not allowed. Thus, the optimal policy is to disallow patent pools whereas private firms would always prefer to form patent pools.

Proposition 3 indicates that when no firm has incentive to litigate, we have a paradoxical result with complementary patents (i.e., $\Delta>\Delta *=\widetilde{R} * / 2$ ): patent pools should be allowed and the monopoly be preserved exactly when the patents are most suspect and have little value (the shaded area in Figure 3). The reason is that unless there is a third party that has a stake in the invalidation of the patents the alternative is the perpetuation of duopoly, which is worse than monopoly in the case of complementary patents. Public policy in this case should be geared towards providing incentives for third parties to invalidate weak patents. 


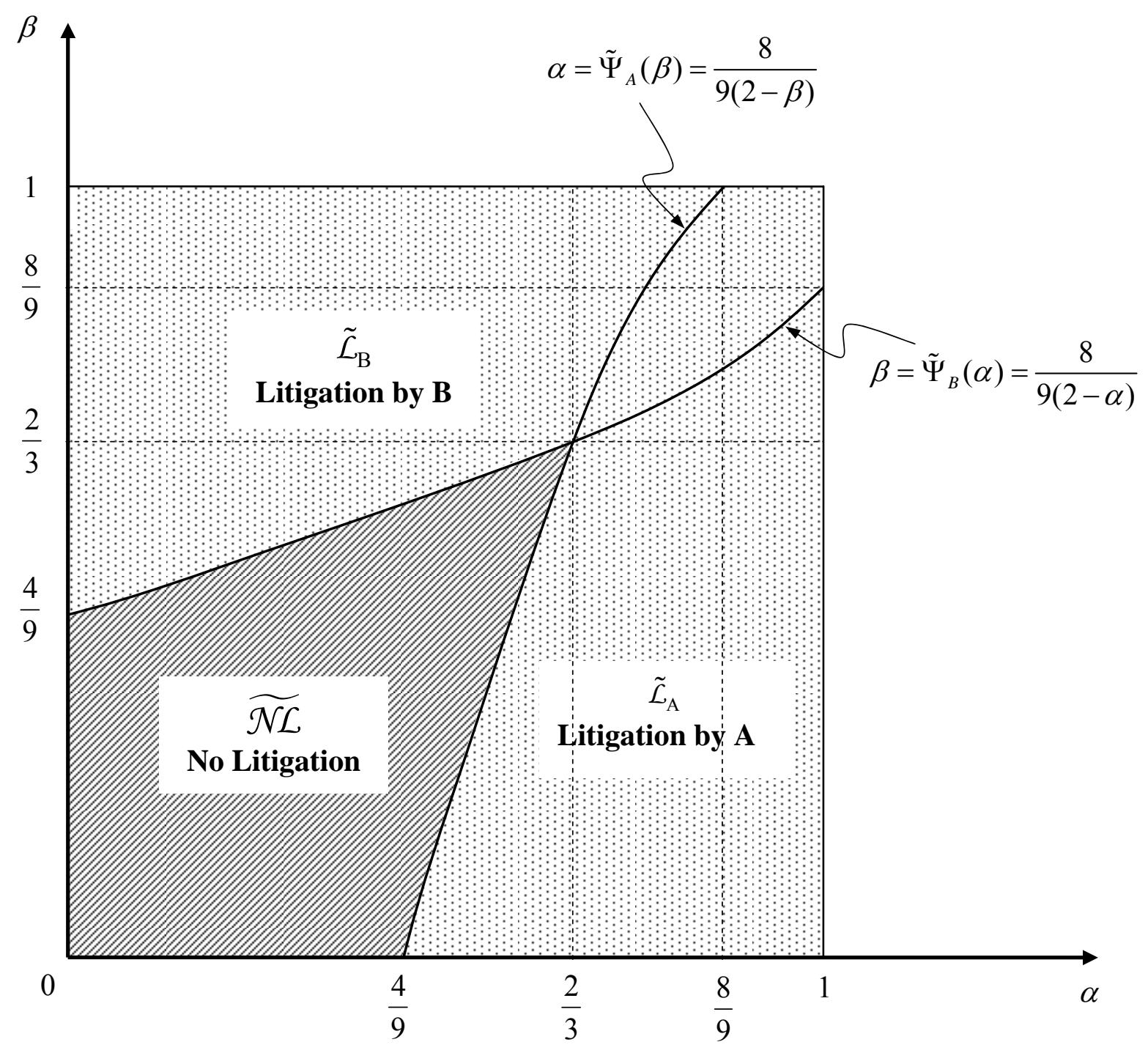

Figure 3: Discrepancy between Private and Social Incentives to Litigate $(\Delta \geq V / 2)$

My discussion so far has focused on the case in which litigation costs are negligible. The consideration of litigation costs changes my welfare results in a predictable way. In particular, there can be regions of parameters in which ex ante patent pools are welfare-enhancing especially when litigation costs are significant. However, it does not change the main message of the paper, which is that ex ante patent pools should not be allowed for patents of suspect validity if firms have incentives to litigate. 
According to a recent survey by the American Intellectual Property Law Association, typical patent litigation costs are estimated to be around $\$ 1$ million through the discovery stage and $\$ 2$ million through any appeal process for cases in which the stakes are between $\$ 1-25$ million. ${ }^{27}$ Figure 4 describes a typical case with litigation costs that illustrates the discrepancy between private and social incentives to form ex ante patent pools, with the assumption that litigation costs are about one tenth of the profits the firms can receive as a patent pool member $\left(\chi=.1 \tilde{\Pi}^{D}\right) \cdot{ }^{28}$ Under this assumption on litigation costs, it can be shown that $\tilde{\mathcal{L}}_{\mathrm{A}}=\left\{(\alpha, \beta) \in[0,1]^{2} \mid \alpha>\Psi_{A}(\beta)=\frac{89}{90(2-\beta)}\right\}$ and $\tilde{\mathcal{L}}_{\mathrm{B}}=\left\{(\alpha, \beta) \in[0,1]^{2} \mid \beta>\Psi_{B}(\alpha)=\frac{89}{90(2-\alpha)}\right\}$, and patent pools should be allowed only when $\beta \geq 1-\frac{1}{5(1-\alpha)}$ if $(\alpha, \beta) \in \tilde{\mathcal{L}}$.

${ }^{27}$ American Intellectual Property Law Association, Report of the Economic Survey 2003. See also Miller (2004).

28 If the stakes in patent litigation are measured by the difference in the expected payoffs between the case in which its own patent is validated and the case in which it is invalidated, they also depend on the probability that the other firm's patent is validated. Assuming that the other firm's patent is upheld with probability $1 / 2$, the figure essentially assumes that the litigation costs are approximately $6.7 \%$ of the stake in litigation, which seems to be roughly consistent with the ratio of average litigation costs to stakes in the survey by the American Intellectual Property Law Association. 


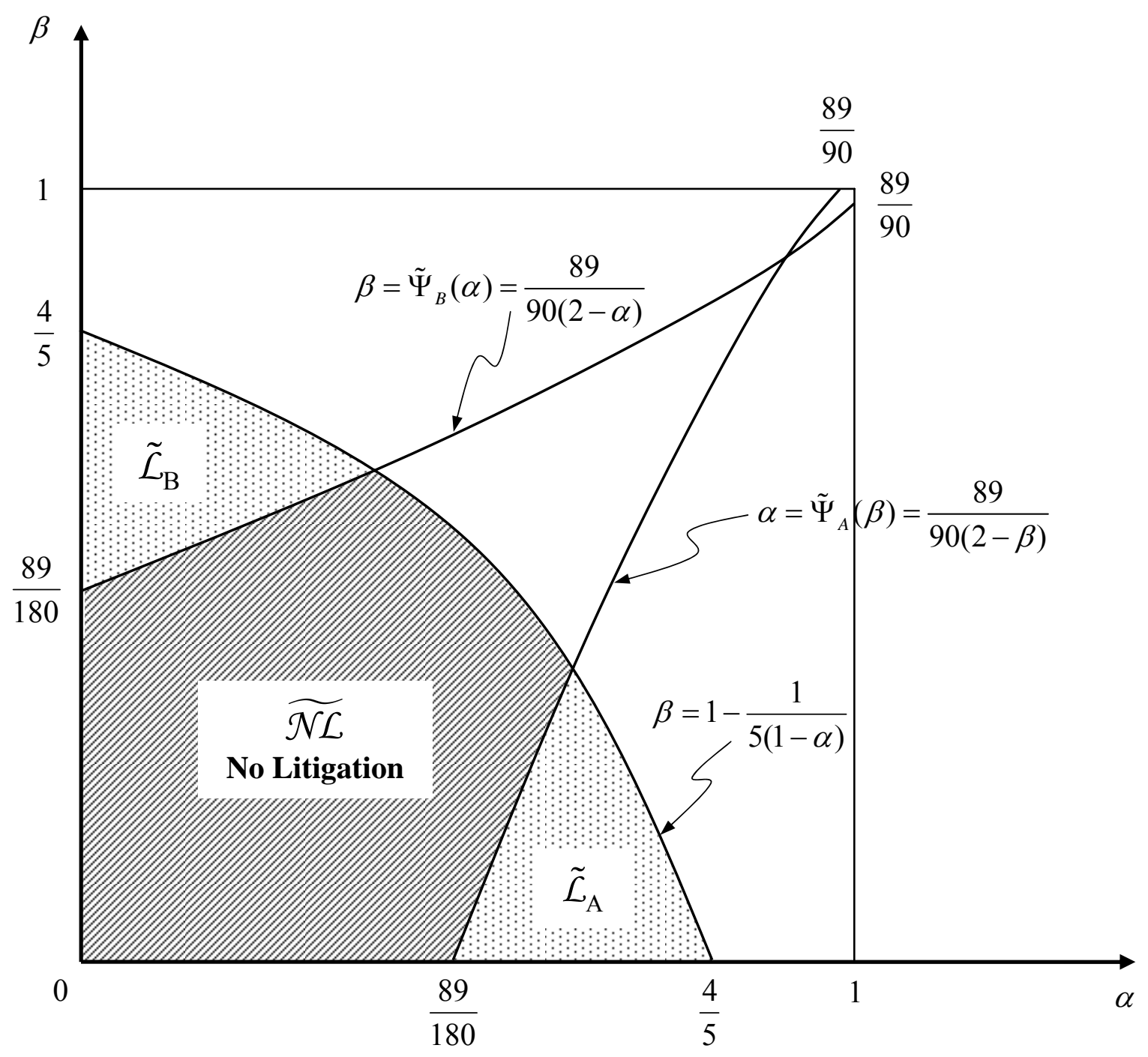

Figure 4: Discrepancy between Private and Social Incentives to Litigate $(\Delta \geq V / 2)$ with Litigation Costs

\section{Disputes over Priority and Correlation in the Probability of Validity}

Up to now I have assumed that the probability of validity of each patent is independent of any others. This would be an appropriate assumption in the case of complementary patents. If the dispute concerns substitute patents, it would be a reasonable assumption if the technologies of the two disputed patents were developed by taking completely different research approaches. For instance, in the case of EPO used 
for treating anemia, Genetics Institute had a patent on a method for purifying EPO from natural sources while Amgen had a patent on a process for using recombinant DNA to make EPO (Viscusi, Vernon, and Harrington, 1995). However, in the case of substitute patents, there could be situations in which both patents essentially cover the same product and the dispute is on priority. Then, the validity of these two patents would be correlated since only one firm can prevail in the court. In this section, I consider an extension and check the robustness of the model to changes in the nature of disputes and the possibility of correlation in the probability of patent validity.

To be more precise, consider a situation where two firms, A and B, are involved in a patent dispute. These two firms have conflicting patents for a new product in that the relative priority of their patents is at stake. ${ }^{29}$ The discovery process of the patent suit may reveal certain earlier inventions suggesting that these two firms' claims are not sufficiently novel to satisfy patent law standards of patentability. One possibility of the patent suit, therefore, is that both patents are held invalid. This type of uncertainty in the outcome of a patent suit is captured by a probability $\alpha$ that the disputed patents satisfy the novelty requirement. ${ }^{30}$ For simplicity, let me assume, conditional on these patents satisfying the novelty requirement, that the probability of one firm's patent having priority over the other is the same across the two firms, with each firm being equally likely to win in the suit. In other words, these two firms have the same probability of $\alpha / 2$ that their patents will be upheld if they are contested in court. With the remaining

\footnotetext{
${ }^{29}$ Disputes over priority are known as patent interferences.

${ }^{30}$ See Scotchmer (1991) for an economic analysis of the novelty requirement in a model of sequential innovations.
} 
probability of $(1-\alpha)$, both patents are held invalid. These probabilities are assumed to be known and shared by both parties.

In this case with substitute patents, it is clear that the optimal ex post patent pool policy is not to allow patent pools. By Proposition 3, we also know that ex ante patent pools should not be allowed if firms have incentives to litigate in the absence of ex ante pools and the litigation is negligible. If firms do not have any incentives to litigate, the ex ante optimal policy is the same as the ex post optimal policy, that is, no ex ante patent pools should be allowed.

Proposition 4. In the case of substitute patents with uncertainty concerning novelty requirement and priority, neither ex ante nor ex post patent pools should be allowed.

Given the simplicity of the optimal patent policy in this case, we now focus on the discrepancy between private and social incentives to litigate. For simplicity, let me assume away any legal costs involved in the litigation process. Then each firm in dispute has the following expected payoff from the patent suit.

$$
V_{A}^{L}=V_{B}^{L}=\frac{\alpha}{2} \Pi^{\mathrm{M}}
$$

If these two firms choose to coexist, each firm has a duopoly profit of $\Pi^{\mathrm{D}}$ for sure, assuming no further entry:

$$
V_{A}^{N L}=V_{B}^{N L}=\Pi^{\mathrm{D}}
$$

Therefore, they will litigate if $\alpha \geq \frac{2 \Pi^{D}}{\Pi^{M}}$. 
Now let us analyze the incentive to litigate from a social planner's viewpoint. Assume that industry structure becomes perfectly competitive due to free entry when the patents are invalidated. Then, the social welfare resulting from the patent suit is:

$$
S W^{L}=\alpha W^{M}+(1-\alpha) W^{C}
$$

The social welfare without litigation is given by:

$$
S W^{N L}=W^{D}
$$

Therefore, litigation is preferred from the social planner's viewpoint if $\alpha \leq \frac{W^{C}-W^{D}}{W^{C}-W^{M}}$.

Notice that when the patents are substitutes and the nature of disputes is relative priority, invalidation of one patent does not imply that the technology is freely available. In fact, invalidation of only one patent leads to a monopoly situation. Thus, it is natural to assume that $\mathrm{W}^{\mathrm{C}}>\mathrm{W}^{\mathrm{D}}>\mathrm{W}^{\mathrm{M}}$ in this case.

As an example, consider Cournot competition with linear demands and constant marginal costs: $P=a-Q$ and $M C=c$, where $a>c$. It can be easily verified that litigation is privately optimal if $\alpha \geq 8 / 9$, whereas litigation is socially optimal if $\alpha \leq$ 20/27. Unless $\alpha \in[20 / 27,8 / 9]$, there is a conflict between the social and private incentives to litigate. In particular, private firms prefer to litigate when the probability of validity is high whereas the social planner prefers litigation when the probability of validity is low.

The example above also demonstrates the inadequacy of the Shapiro rule (2001) proposed for patent settlement once we account for incentives to litigate. It is easy to see that with substitute patents unrestricted negotiation between the two patentees will always lead to a collusive outcome with social welfare loss. Thus, any licensing 
arrangement involving substitute patents should be subject to restrictions on the contractual terms. Shapiro (2003) recommends a general rule for evaluating proposed patent settlements, which is to require that "the proposed settlement generate at least as much surplus for consumers as they would have enjoyed had the settlement not been reached and the dispute instead been resolved through litigation."31 The rationale for such a rule is that it fully respects intellectual property rights while protecting the interest of consumers.

To show the non-applicability of the Shaprio Rule when both patents are weak, consider the Cournot competition example above with a linear demand. Let CSM, ${ }_{C S}{ }^{C}$ denote consumer surplus when the market structures are monopoly (patents satisfy the novelty requirement and one of the firms wins the priority suit) and perfectly competitive (both patents are invalidated):

$$
\mathrm{CS}^{\mathrm{M}}=\frac{(a-c)^{2}}{8}, \mathrm{CS}^{\mathrm{C}}=\frac{(a-c)^{2}}{2}
$$

This implies that the expected consumer surplus from ongoing litigation is

$$
\begin{aligned}
\overline{C S} & =\alpha \mathrm{CS}^{\mathrm{M}}+(1-\alpha) \mathrm{CS} C \\
& =\frac{4-3 \alpha}{8}(a-c)^{2}
\end{aligned}
$$

Let $\bar{p}$ denote the price that results from the settlement between the two firms. Then, to maintain the expected consumer surplus from litigation $\overline{C S}$, the maximum settlement price allowed would be

${ }^{31}$ Shapiro (2003), p. 393. 


$$
\bar{p}=k c+(1-k) a, \text { where } k=\sqrt{\frac{4-3 \alpha}{4}}^{32}
$$

A natural way to implement the outcome would be a cross-licensing arrangement with a per-unit royalty rate. More specifically, with a royalty rate of $r$, each firm's marginal cost becomes $c+r$. With Cournot competition and the linear demand curve, each firm produces $[a-(c+r)] / 3$ and the market price is $[a+2(c+r)] / 3$. Thus, the royalty rate of $r=[1-(3 k / 2)](a-c)$ will induce the market price of $\bar{p}=k c+(1-k) a$.

The Shapiro rule is certainly a sensible rule once firms are already engaged in patent disputes. The problem is that the rule has no bite when their patents are weak since neither of them will have an incentive to litigate in the first place. Instead, they would prefer to maintain the status quo without challenging each other's patents. More precisely, if they litigate and the Shapiro rule is enforced for settlement, each firm's profit would be $[(1-k)(a-c)]^{2}$. In contrast, if they adopt the strategy of coexistence without challenging each other, they can secure the duopoly profits of $(a-c)^{2} / 9$. Thus, when $k>2 / 3$, or equivalently if $\alpha<20 / 27$, neither firm has an incentive to challenge the other's patent. As a result, the distortion due to the weak patents will not be corrected through the litigation process.

${ }^{32}$ Let CS ( $\left.p\right)$ be the level of consumer surplus when the market price is $p$. With the linear inverse demand curve of $p=a-Q, \operatorname{CS}(p)=(a-p)^{2} / 2$. Thus, $\bar{p}$ is defined by $\operatorname{CS}(\bar{p})=\overline{C S}$, which yields the expression in equation (27). 


\section{Concluding Remarks}

In this paper I have developed a simple model of patent pools that take place in the shadow of patent litigation. I analyzed private incentives to litigate and compared them with the social incentives. It was shown that pooling arrangements can have the effect of sheltering invalid patents from challenges. In addition, antitrust implications of patent pools were considered. In particular, patent pools should not be permitted until after patentees have challenged the validity of each other's patents if litigation costs are not too large.

The analysis of the paper points out, inter aila, the serious lack of private incentives to weed out patents of suspect value through litigation. This is especially troubling in view of the recent explosion of patent awards triggered by U.S. patent reform in the last two decades and escalating litigation costs. ${ }^{33}$ This development has led some commentators to even question whether the proliferation of patent awards may impede rather than promote innovation (Gallini, 2002). Considering ex parte relationships between patent applicants and examiners, it is important to subject patents of dubious merit to adversarial contests in the court. The current patent system, however, suffers from a free-rider problem. To mitigate the problem, we may seriously consider adopting a European style administrative opposition procedure in the US system and/or allowing the participation of third parties through pre-grant publication of patent applications. ${ }^{34}$

\footnotetext{
33 See Lerner (1995) for an empirical analysis of patent litigation. He estimates the costs of patent litigation started in 1991 at about \$1 billion, which amounts to 27 percent of basic R\&D expenditures by US firms in the same year.

34 See Jaffe and Lerner (2004) and Choi (2005) for more discussion on patent system reform.
} 
I conclude by mentioning a few avenues of research to extend the simple model in this paper. First, I have assumed a symmetric information structure in which all potential litigants have the same beliefs about the validity, scope, and enforceability of the patents considered. This assumption can be suspect if the patentee has better information regarding validity since she may know the potential weaknesses of the patent (Meurer, 1989). Without symmetric beliefs, mutual optimism concerning the outcome of litigation could lead to patent disputes in court. Out-of-court settlement then can be explained by the revelation of a new piece of information that leads to shared beliefs. Consideration of such private information introduces a whole new set of problems and allows much richer dynamics. The mere decision to bring a suit, for instance, can have informational content especially when out-of-court settlement is possible. In addition, if there is private information held by either of the disputing parties regarding the validity of the patent, litigation behavior in court can have signaling value and potentially influence the terms of licensing just as predatory behavior of the incumbent can affect the terms of a merger with the entrant (Saloner, 1987). This is an important agenda for future research.

Michigan State University, U.S.A. and Yonsei University, Korea 


\section{References}

Allison, J. R. and M. A. Lemley, "Empirical Analysis of the Validity of Litigated Patents," American Intellectual Property Law Association Quarterly Journal 26 (1998), 185-275.

Chappell, J., "Legal Snafus Abound,” Electronic News (September 2, 2002).

Choi, J. P., "Patent Litigation as an Information Revelation Mechanism," American Economic Review 88 (1998), 1249-1263.

Choi, J. P., "Patent Pools and Cross-Licensing in the Shadow of Patent Litigation" CESifo Working Paper Series No. 1070, November 2003.

Choi, J. P., "Live and Let Live: A Tale of Weak Patents," Journal of European Economic Association 3 (2005), 724-733.

Cournot, A., Researches into the Mathematical Principles of the Theory of Wealth, originally published in French (1838), translated by N. Bacon (New York: Macmillan, 1927).

Farrell, Joseph and Shapiro, Carl, "How Strong Are Weak Patents?” American Economic Review 98 (2008), 1347-1369.

Fudenberg, D. and J. Tirole, Game Theory (Cambridge, MA: MIT Press, 1991).

Gallini, N. T., "The Economics of Patents: Lessons from Recent U.S. Patent Reform,” Journal of Economic Perspectives 16 (2002), 131-154.

Gilbert, R. J., “Antitrust for Patent Pools: A Century of Policy Evolution,” Stanford Technology Law Review 3 (2004), also available at http://stlr.stanford.edu/STLR/Articles/04_STLR_3/

Green, J. and S. Scotchmer, "On the Division of Profit in Sequential Innovation," Rand 
Journal of Economics 26, (1995), 20-33.

Jaffe, A. B. and J. Lerner, Innovation and Its Discontents: How Our Broken Patent System is Endangering Innovation and Progress, and What to Do About It (Princeton, NJ: Princeton University Press, 2004).

Lanjouw, J. O. and M. Schankerman, "Characteristics of Patent Litigation : A Window on Competition," Rand Journal of Economics 32 (2001), 129-151. and ___ "Enforcing Intellectual Property Rights: Suits, Settlements and the Explosion in Patent Litigation," unpublished manuscript, June 2002

Lemley, M. A. and C. Shapiro, "Probabilistic Patents," Journal of Economic Perspectives 19 (2005), 75-98.

Lerner, J., "Patenting in the Shadow of Competitors," Journal of Law and Economics 38 (1995), 463-495. and J. Tirole, "Efficient Patent Pools," American Economic Review 94 (2004), 691711.

, M. Strojwas and J. Tirole, “Cooperative Marketing Agreements between Competitors: Evidence from Patent Pools," Harvard NOMO Working Paper No. 03-25, April 2003.

Meurer, M. J., "The Settlement of Patent Litigation," Rand Journal of Economics 20 (1989), 77-91.

Miller, J. S., "Building a Better Bounty: Litigation-Stage Rewards for Defeating Patents," Berkeley Technology Law Journal 19 (2004), 667-740.

O’Donoghue, T., S. Scotchmer and J.-F. Thisse, "Patent Breadth, Patent Life and the Pace of Technological Progress," Journal of Economics and Management 
Strategy 6 (1998), 1-32.

Priest, G. L., "Cartels and Patent License Arrangements," Journal of Law and Economics 20 (1977), 309-377.

Saloner, G., "Predation, Mergers and Incomplete Information," Rand Journal of Economics 18 (1987), 165-186.

Scotchmer, S., "Standing on the Shoulders of Giants: Cumulative Research and the Patent Law," Journal of Economic Perspective 5 (1991), 29-41.

Shapiro, C., "Navigating the Patent Thicket: Cross Licenses, Patent Pools, and Standard Setting," in A. Jaffe, J. Lerner, and S. Stern, eds., Innovation Policy and the Economy, Vol. 1, (Cambridge, MA: MIT Press, 2001), 119-150. , “Antitrust Limits to Patent Settlements," Rand Journal of Economics 34 (2003), $391-411$.

U.S. Department of Justice and the Federal Trade Commission, Antitrust Guide Lines for the Licensing and Acquisition of Intellectual Property, 1995.

Viscusi, W. K., J. M. Vernon and J. E. Harrington, Economics of Regulation and Antitrust, 2nd edition (Cambridge, MA: MIT Press, 1995). 